Article

\title{
Evaluation of Bio-Based Extraction Methods by Spectroscopic Methods
}

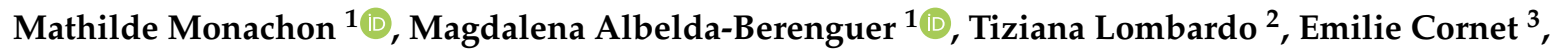 \\ Friederike Moll-Dau ${ }^{4}$, Janet Schramm ${ }^{2}$, Katharina Schmidt-Ott ${ }^{2}$ and Edith Joseph ${ }^{1,3, *}$ \\ 1 Laboratory of Technologies for Heritage Materials, University of Neuchâtel, 2000 Neuchâtel, Switzerland; \\ mathilde.monachon@unine.ch (M.M.); magdalena.albelda@unine.ch (M.A.-B.) \\ 2 Swiss National Museum, 8910 Affoltern am Albis, Switzerland; tiziana.lombardo@nationalmuseum.ch (T.L.); \\ janet.schramm@nationalmuseum.ch (J.S.); katharina.schmidt-ott@nationalmuseum.ch (K.S.-O.) \\ 3 Haute Ecole Arc Conservation-Restauration, HES-SO University of Applied Sciences and Arts Western \\ Switzerland, 2000 Neuchâtel, Switzerland; emilie.cornet@he-arc.ch \\ 4 Archaeological Service of Canton Bern, 3001 Bern, Switzerland; friederike.moll-dau@be.ch \\ * Correspondence: edith.joseph@unine.ch or edith.joseph@he-arc.ch; Tel.: +41-327-182-235 or +41-329-301-939
}

Received: 31 January 2020; Accepted: 22 February 2020; Published: 24 February 2020

\begin{abstract}
New technologies are in development regarding the preservation of waterlogged archaeological wood items contaminated with $\mathrm{Fe} / \mathrm{S}$ species. To this purpose, a bio-based treatment to extract these harmful species before further damages occur is presented. Thiobacillus denitrificans and desferoxamine were employed based on their specific properties to solubilize iron sulfides and uptake iron. The biological treatment was compared with oxidizing and complexing agents (sodium persulfate and ethylene diamine tetraacetate) traditionally used in conservation-restoration. Mock-ups of fresh balsa as well as fresh and archeological oak and pinewood were prepared to simulate degraded waterlogged wood by immersion in corrosive Fe/S solutions. The efficiency of both biological and chemical extraction methods was evaluated through ATR-FTIR and Raman spectroscopies and validated by statistical approach. Results showed that treatments did not affect the wood composition, meaning that no wood degradation was induced. However, the chemical method tended to bleach the samples and after treatment, reduced sulfur species were still identified by Raman analyses. Finally, statistical approaches allowed validating ATR-FTIR results.
\end{abstract}

Keywords: waterlogged wood; bio-based extraction; wood degradation; Raman spectroscopy; statistic approach

\section{Introduction}

Anoxic environments promote the preservation of waterlogged archaeological wooden objects. When artefacts are, for example, buried in sediments, the surrounding environment allows the wood structure to perdure [1]. The cellulosic content is however subjected to a slow deterioration by erosion bacteria (EB) as primary wood degraders under these conditions [2,3].

First, the lignocellulose structure of the cell walls is broken by EB [4,5]. The wood surface is degraded allowing the bacterial invasion to reach the cell lumen and continuing through the cellulose-rich layer. In this layer, the crystallized cellulose is converted into an amorphous substance $[1,6,7]$ that is then used by secondary wood degraders such as sulfate-reducing bacteria (SRB) as carbon and energy source. In parallel, in sulfate-rich environments, hydrogen sulfide $\mathrm{H}_{2} \mathrm{~S}$ is produced by the reaction of SRB with organic carbohydrates of wood, according to Equation (1) [8]:

$$
2\left(\mathrm{CH}_{2} \mathrm{O}\right)+\mathrm{SO}_{4}{ }^{2-}+2 \mathrm{H}^{+} \rightarrow \mathrm{H}_{2} \mathrm{~S}+2 \mathrm{H}_{2} \mathrm{O}+2 \mathrm{CO}_{2}
$$


$\mathrm{H}_{2} \mathrm{~S}$ diffuses within the wood and reacts with iron ions, if present (i.e., as nails or in the burial environment). Iron sulfides are then formed and accumulated within the wood timbers according to Equation (2) [4,9]:

$$
\mathrm{Fe}^{2+}+\mathrm{H}_{2} \mathrm{~S} \rightarrow \mathrm{FeS}+2 \mathrm{H}^{+}
$$

Transfer of the artefacts from an anoxic to an oxic environment reveals severe conservation issues. Indeed, iron sulfides are oxygen-sensitive [10]. Acidification and salts efflorescence occur leading to irreversible physical and chemical damages. The $\mathrm{pH}$ drop enhances the degradation of cellulose through an acidic hydrolysis resulting in a loss of strength. In addition, formed iron oxides, iron sulfates and/or elemental sulfur induce cracks of the cell structure as these salts are more voluminous than their precursor iron sulfides [11]. Moreover, iron itself catalyzes the oxidation of sulfur compounds and cellulose degradation, accelerating the decay process [12,13].

Iron and sulfur accumulation within waterlogged archaeological wood is of great concern for conservation and preservation. It occurs frequently in marine environments but could also occur on sweet water finds. Several important wooden cultural heritage artefacts such as the Vasa warship in Sweden or the Mary Rose in United Kingdom present acidification and salt precipitation issues and require a long-term monitoring [14].

Usually, polyethylene glycol (PEG) is the main consolidation agent employed, either by spraying or immersion [5,12]. However, this method does not prevent from acidification and salts efflorescence. Moreover, iron keeps corroding in contact with moist PEG inducing even more degradation of the wooden structure [15]. Complexing agents such as derivatives of ethylene diamine tetra acetic (EDTA), employed to extract iron, present high extraction yields but do not avoid wood swelling and are time-consuming [16]. In addition, neutralizing methods are also performed to remediate the acidification. Alkaline baths and ammonia gas are the most efficient methods employed so far but can induce holocellulose degradation [4].

Alternatively, less aggressive methods are currently being developed. For instance, bio-based technologies have proven to be sustainable solutions for the preservation of cultural artefacts [17]. Microbial processes can be used for consolidation, cleaning or inhibition of reactive corrosion products while reducing the toxicity related to traditionally used treatments [18]. For metal conservation, Beauvaria bassiana fungal strain produces oxalic acid in presence of toxic metals such as copper. The copper is then transformed into copper oxalates. Applied on outdoor bronze sculptures, this biotechnology allows forming a protective and stable layer preventing the object from further degradation and leaching [19]. Microorganisms can also be employed to stabilize corroded layers of archaeological iron artefacts and akaganeite $\beta-\mathrm{FeOOH}$, a chlorine-containing iron oxyhydroxide, can be converted into chemically stable vivianite $\mathrm{Fe}_{3}\left(\mathrm{PO}_{4}\right)_{2} \cdot 8 \mathrm{H}_{2} \mathrm{O}$, siderite $\mathrm{FeCO}_{3}$ or magnetite $\mathrm{Fe}_{3} \mathrm{O}_{4}$. As well, few studies related bio-based conservation methods on waterlogged archaeological wood and the removal of mackinawite $\mathrm{FeS}$ and pyrite $\mathrm{FeS}_{2}$, the main iron sulfides detected in such artefacts [20].

The goal of the present research is to develop an innovative, green and sustainable extraction method using the specific capacities of some microorganisms, such as Thiobacillus denitrificans, to extract harmful $\mathrm{Fe} / \mathrm{S}$ species. In fact, T. denitrificans, a facultative anaerobe bacterium, can employ nitrate $\mathrm{NO}_{3}{ }^{-}$ as electron donor to oxidize sulfur compounds at neutral $\mathrm{pH}$. Several case studies showed its faculty to dissolve iron sulfide compounds [14,21]:

$$
5 \mathrm{FeS}+8 \mathrm{NO}_{3}{ }^{-}+8 \mathrm{H}^{+} \rightarrow 5 \mathrm{Fe}^{2+}+5 \mathrm{SO}_{4}{ }^{2-}+4 \mathrm{~N}_{2}+4 \mathrm{H}_{2} \mathrm{O}
$$

In addition, siderophores were investigated for the extraction of iron on organic materials [22]. In fact, siderophores are produced by many bacteria under iron-deficient conditions and they present the highest iron affinity, allowing their use in pharmacology, agriculture, medicine and other applications [23]. For example, the application of siderophores was investigated on paper and wooden artefacts to remove iron staining [24]. The results showed that siderophores were the 
most effective regarding the extraction of iron in comparison to commonly used complexing agents. They represent a promising green alternative to current chemical iron extraction methods [25].

The efficiency of the proposed bio-based treatment regarding $\mathrm{Fe} / \mathrm{S}$ species extraction is evaluated by comparing with the main chemical methods usually employed on different wood mock-ups. Further consolidation with PEG and freeze-drying is also foreseen to check the compatibility of bioremediation with the following consolidation and drying steps. Attenuated total reflectance infrared (ATR-FTIR) and Raman spectroscopies analyses were performed to evaluate the wood degradation and Fe/S extraction rates. First results showed promising results with the biological treatment as the appearance of biologically treated samples was less impacted than the chemically treated samples. Moreover, ATR-FTIR analyses did not show any wood degradation and Raman revealed that reduced sulfur compounds were still present only after chemical extraction. Statistical analyses were also performed on the different datasets to validate the previous observations achieved.

\section{Materials and Methods}

\subsection{Wood Samples}

Three wood species were selected: balsa, oak and pine. Balsa wood (Ochroma pyramidale) is a light and porous wood, with a structure similar to the one of waterlogged archaeological wood. It has already been used in some research projects in mock-ups to model waterlogged wood [26]. Oak (Quercus sp.) and pine (Pinus sp.) are the main wood species found on waterlogged wood artefacts and the most described cases in literature [16,27]. Fresh oak wood has been also reported as a mock-up to mimic waterlogged wood $[13,28]$.

Fresh and archaeological wood samples were used. Fresh balsa was purchased from Coop Brico + Loisirs (Neuchâtel, Switzerland). Fresh oak and pine were provided from a carpenter, J.F. Liabeuf (Cernier, Switzerland). Concerning archaeologic samples, poles and boards of Neolithic oak and pine (respectively) were provided by the Archaeological Service of Bern Canton (ADB) and two Neolithic oak poles by the Swiss National Museum (SNM).

Cubes samples of $2 \times 2 \times 2 \mathrm{~cm}^{3}$ were cut. Concerning archaeological wood, the samples were cut on the external layer of the poles (earlywood) and following the wood ring to have homogeneous samples sets. All the samples present the transversal (Tv), Tangential (Tg) and Radial (Rd) cutting sections.

For each wood species and type, 10 sets of 19 samples were prepared. For each set, one sample was kept as reference, on which no artificial contamination or extraction was performed. The set distribution is described in Table 1.

Table 1. Sample information and distribution based on wood species, wood type, artificial contamination and provenance (ADB: Archaeological Service of Bern Canton and SNM: Swiss National Museum).

\begin{tabular}{ccccc}
\hline Set Name & Wood Species & Wood Type & Artificially Contaminated & Wood Origin \\
\hline A1 & Balsa & Fresh & Yes & Commercial \\
A2 & Balsa & Fresh & Yes & Commercial \\
B & Oak & Fresh & Yes & Carpenter \\
C & Oak & Archaeologic & No & ADB \\
D1 & Oak & Archaeologic & No & ADB \\
D2 & Oak & Archaeologic & Yes & Carpenter \\
E & Pine & Fresh & Yes & ADB \\
F & Pine & Archaeologic & No & ADB \\
G1 & Pine & Archaeologic & No & SNM \\
G2 & Oak & Archaeologic & &
\end{tabular}

All samples were stored in degassed deionized water as stock solution. Sets A1, A2, B, C, E and $\mathrm{F}$ were artificially contaminated with iron and sulfur species according to the protocol described in Albelda-Berenguer et al. [14]. The purpose of this impregnation is to form iron sulfides compounds 
such as mackinawite $(\mathrm{FeS})$ and/or pyrite $\left(\mathrm{FeS}_{2}\right)$. A water pre-immersion treatment under vacuum (600 mbars) was also applied for sets A1, A2, B and E before impregnation to enhance the desired wood degradation and to simulate the state of degradation observed on real waterlogged wood artefacts. Regarding D1, D2, G1 and G2 sets, spot tests to detect $\mathrm{Fe}^{2+}, \mathrm{Fe}^{3+}$, sulfides and sulfates were performed and revealed the presence of iron and sulfates and in some parts sulfides. The tests were performed with potassium thiocyanate 33\% and barium chloride to detect iron and sulfates, respectively. Machery-Nagel ${ }^{\circledR}$ test paper $n^{\circ} 90761$ (Fisher Scientific AG, Reinach, Switzerland) was employed for sulfides detection [29].

\subsection{Extraction Methods}

Each set was photographically documented before and after extraction (Figure 1). Before extraction, the samples were put in $400 \mathrm{~mL}$ of deionized water and sonicated for 2 and then $4 \mathrm{~min}$. The water was changed between the two-sonication baths. The sonication allows removing the chemicals employed for impregnation. Two baths were necessary to have a clear solution. Six samples per set were used for each extraction method tested and labelled as biologically treated (BT) and chemically treated (CT) samples respectively (see Sections 2.2.1 and 2.2.2). In parallel, six samples remained in deionized water as control and labelled as non-treated (NT) samples. The volume of extraction solution was set to $200 \mathrm{~mL}$. At the end of treatment, BT and CT samples were put in degassed deionized water and several cycles of $2 \times 20$ min vacuum ( 1 mbars) followed by 1 h sonication were applied on the samples until constant $\mathrm{pH}$ was reached and storage solution conductivity was in the range $10-30 \mu \mathrm{S} / \mathrm{cm}^{-1}$ (as the rinsing water).

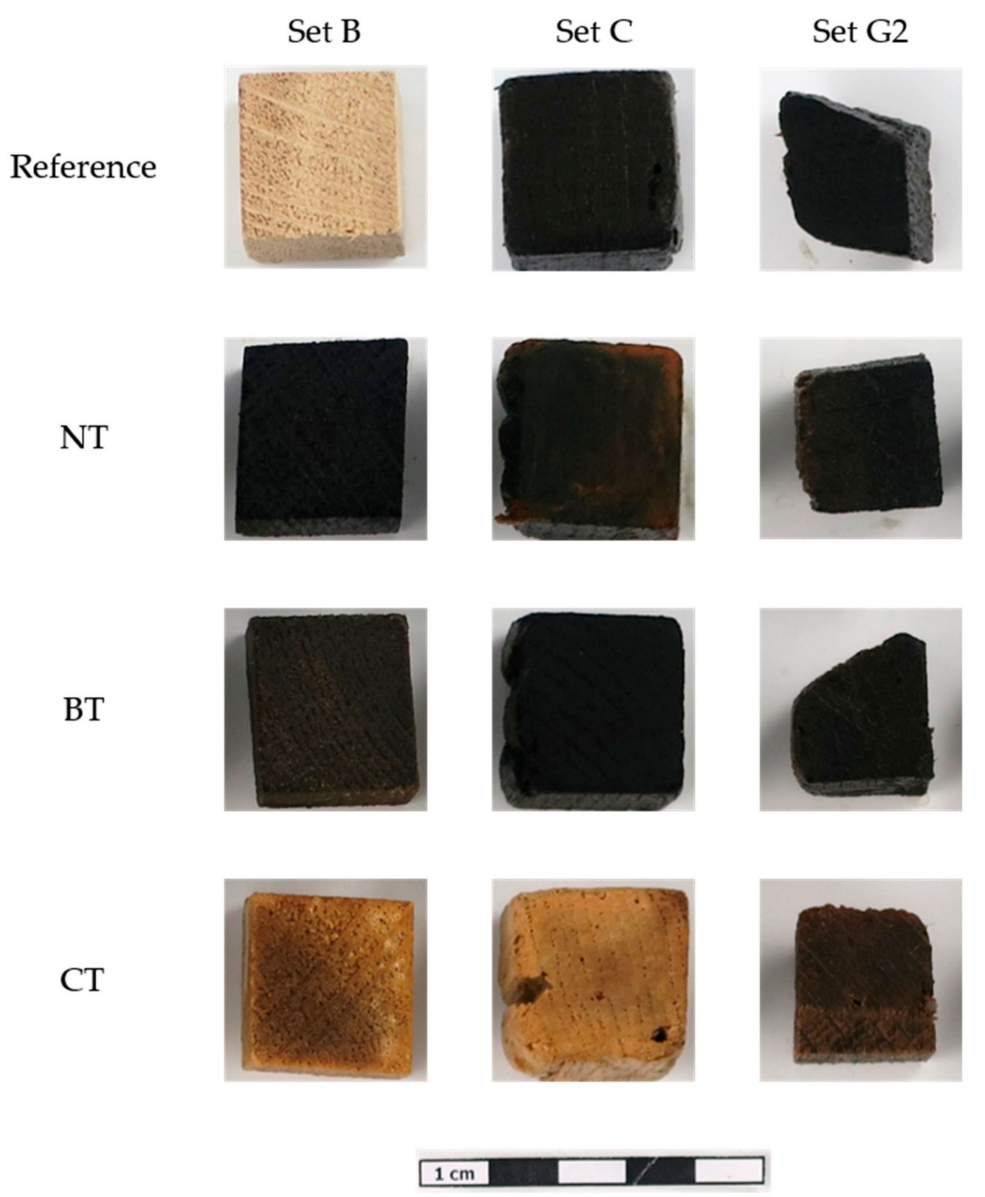

Figure 1. Appearance of reference, untreated (NT), biologically treated (BT) and chemically treated (CT) samples for sets B, C and G2 (fresh and archaeological artificially contaminated and archeological oak wood, respectively). 


\subsubsection{Biological Extraction}

T. denitrificans (DSMZ 12475) was obtained from the German Collection of Microorganisms and Cell Cultures (DMSZ, Braunschweig, Germany). The strain was cultivated using standard anaerobic techniques at $30^{\circ} \mathrm{C}$ in the dark. Desferoxamine (DFO) was purchased as Desferal ${ }^{\circledR}$ (Novartis Pharma Schweiz AG, Basel, Switzerland). The BT samples were immersed in a solution of DFO $84 \mathrm{mM}$ for 10 days. Samples were kept at room temperature and with orbital agitation (100 rpm). After rinsing with deionized water, the samples were immersed with T. denitrificans for 20 days. Samples inoculated with the bacteria were incubated at $30^{\circ} \mathrm{C}$ in darkness without agitation.

\subsubsection{Chemical Extraction}

The applied protocol was based on a previous study [26]. The samples were immersed in sodium persulfate $0.1 \mathrm{M}$ for 1 day to oxidize sulfur species. After rinsing with deionized water, the samples were then immersed in EDTA $0.125 \mathrm{M}$ for 7 days to complex free iron ions. During the whole process, the samples were kept at room temperature without agitation.

\subsection{Analytical Protocol}

\subsubsection{ATR-FTIR Spectroscopy}

Wood degradation was evaluated by Fourier Transform InfraRed spectroscopy. Wood mock-ups were characterized in the $4000-650 \mathrm{~cm}^{-1}$ range using a Nicolet iS5 instrument (Thermo Fisher Scientific, Waltham, MA, USA) equipped with an Attenuated Total Reflectance accessory, with 16 scans, resolution of $4 \mathrm{~cm}^{-1}$ and an analyzed area of $62.5 \mu \mathrm{m}$. Two samples per treatment (BT, CT and NT) per set were analyzed and three spectra per five faces were recorded, for a total of 90 spectra per set. The height of vibrational bands at $1034 \mathrm{~cm}^{-1}$ assigned to holocellulose $\mathrm{H}$ and lignin $\mathrm{L}$, $1158,1374 \mathrm{~cm}^{-1}$ assigned to holocellulose $\mathrm{H}$, cellulose $\mathrm{C}$ and $1506 \mathrm{~cm}^{-1}$ assigned to lignin $\mathrm{L}$ were used to calculated three ratios: $\mathrm{R} 1=\mathrm{I}(1158) / \mathrm{I}(1506), \mathrm{R} 2=\mathrm{I}(1374) / \mathrm{I}(1506)$ and $\mathrm{R} 3=\mathrm{I}(1034) / \mathrm{I}(1506)$ according to literature [30,31]. Bands height of spectra were measured using Rstudio software (Rstudio, Boston, MA, USA) and ChemoSpec package (Bryan A. Hanson, DePauw Univeristy, https: //bryanhanson.github.io/ChemoSpec/index.html). Heights of bands were calculated from the baseline, corrected with a polynomial function, and normalization of the spectra. These ratios allow determining which wood components were affected by the treatments and thus the wood state of degradation.

\subsubsection{Raman Spectroscopy}

Compounds present on the wood samples were identified by Raman spectroscopy. The measurements were performed on wet samples, immersed in their stock solution (degassed water). This methodology allows avoiding the overwarming of the samples that would induce a possible modification of the compounds under the laser excitation.

Analyses were carried out using a LabRam Aramis Horiba instrument (HORIBA Jobin Yvon $\mathrm{GmbH}$, Bensheim, Germany) and LabSpec 5 software with a $632.8 \mathrm{~nm}$ laser, in the range $100-1500 \mathrm{~cm}^{-1}$, with $100 \times$ objective (numerical aperture of 0.9 ) and laser power of $0.99 \mathrm{~mW}$ at the surface of the sample (D1 filter, 10\%), 1800 lines/mm grating, $1000 \mu \mathrm{m}$ confocal pinhole and $100 \mu \mathrm{m}$ spectrometer entrance slit. Two samples per treatment (BT, CT and NT) per set were analyzed. One spectrum at the center of three faces was recorded. Two spectra as routine ones (10 acquisitions of $5 \mathrm{~s}$ ) and as another with a long acquisition $(25 \times 10 \mathrm{secs})$. A total of 18 spectra per set were recorded.

In parallel, reference compounds (mackinawite $\mathrm{FeS}$, goethite $\alpha$-FeOOH, hematite $\mathrm{Fe}_{2} \mathrm{O}_{3}$ ) were synthetized according to Bourdoiseau et al. and Schwertmann [32,33]. These precipitates as well as sulfur (Sigma, $\alpha-\mathrm{S}_{8}$ ) and pyrite (http://www.pierrequiroule.ch/, $\mathrm{FeS}_{2}$ ) were used to create a reference spectral dataset. Spectra were acquired with the same parameters as above. Moreover, water pre-immersed wood and archaeologic samples of different wood types were used to obtain reference spectra of the wood substrates. 


\subsection{Statistic Approach}

Chemometric analyses were performed to validate which extraction method was the most efficient in terms of wood degradation and Fe/S extraction rates. Principal component analyses (PCA) were carried out on all spectroscopic measurements. Deeper investigations were achieved on spectroscopic data with Least Absolute Shrinkage and Selection Operator (LASSO) analyses. Rstudio software was used with the packages Chemospec, ggplot2, and glmnet. The spectra dataset was corrected (baseline, bin, normalization, Savitzky-Golay filter) before any analyses.

\section{Results}

\subsection{ATR-FTIR Spectrosocpy}

Spectra recorded on untreated samples were considered as a starting point $(\mathrm{t} 0)$ for the characterization campaign. Before extraction, differences could be observed between the spectra from fresh and archaeological wood sets (Figure 2A). Vibrational bands at 1034 and $1059 \mathrm{~cm}^{-1}$ were very intense for fresh wood and decreased in intensity for archaeological wood sets. Only set F (Figure 2A, light green line) which is lake pinewood presented a mean spectrum similar to fresh samples. These bands were assigned to $\mathrm{C}-\mathrm{O}$ stretching of holocellulose and lignin [34]. Moreover, the intensity of vibrational band at $1738 \mathrm{~cm}^{-1}$ assigned to $\mathrm{C}=\mathrm{O}$ stretching in xylan, a component of hemicellulose [35], decreased for archaeological wood sets. All these observations suggested a degradation of holocellulose content within the archaeological wood sets. On the contrary, archaeological samples displayed intense band at $1650 \mathrm{~cm}^{-1}$ attributed to $\mathrm{H}_{2} \mathrm{O}$ deformation due to the water absorbed by waterlogged wood during burial time (Figure 2A). The vibrational bands at 1237 and $1267 \mathrm{~cm}^{-1}$ were assigned to C-O stretching (lignin and xylan) and to C-H and O-H wagging (cellulose and xylan) [13,34,35]. Generally, a higher intensity of these bands was observed for fresh wood presenting differences between the wood species.

After extraction, BT and CT extraction methods presented similar spectra while NT samples showed different bands intensities. The bands at 1034 and $1059 \mathrm{~cm}^{-1}$ were still observed for fresh samples (Figure 2B, full lines). However, the intensities of bands in the range $1300-1200 \mathrm{~cm}^{-1}$ decreased. All sets presented adsorbed water with a characteristic band at $1650 \mathrm{~cm}^{-1}$. Archeological samples still had bands less intense in the range $1400-1200 \mathrm{~cm}^{-1}$ suggesting that the degradation of fresh wood was not comparable to in situ degradation (Figure 2B, dashed lines). Finally, none of the sets displayed the band at $1738 \mathrm{~cm}^{-1}$, meaning that xylan content was probably degraded for all wood samples (Figure 2B).

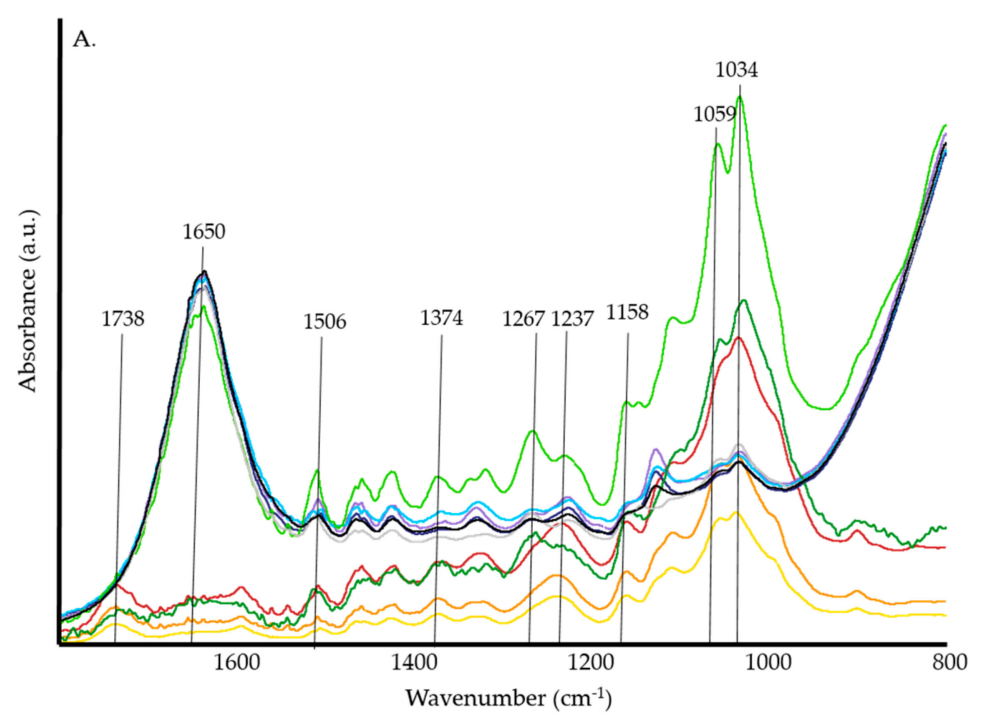

Figure 2. Cont. 


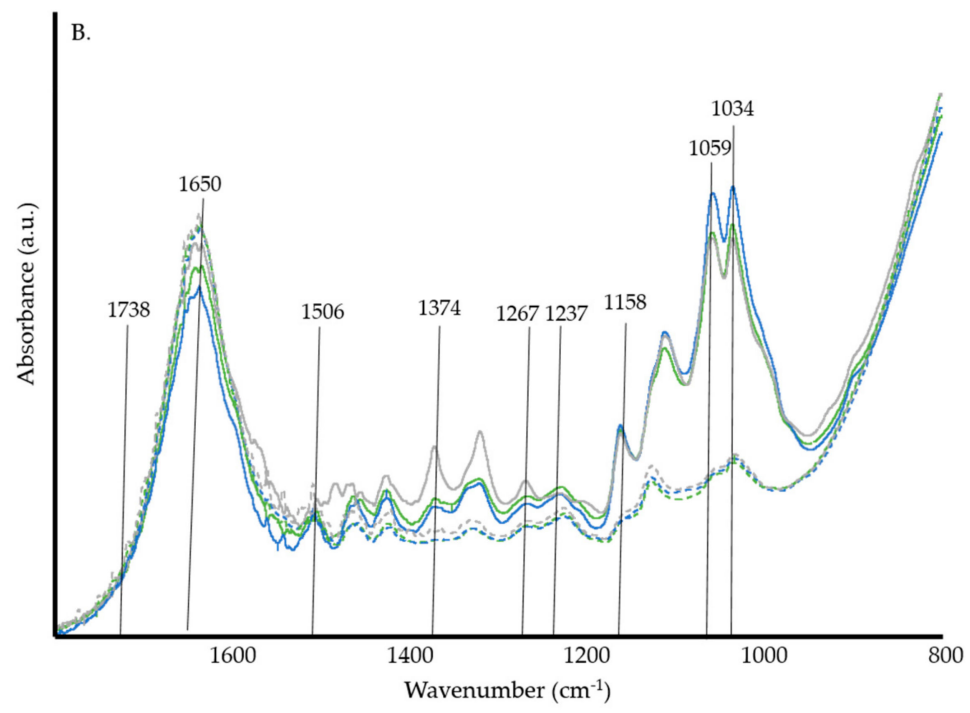

Figure 2. Mean ATR-FTIR spectra (A) before extraction for balsa sets A1 (yellow) and A2 (orange), oak sets B (red), C (purple), D1 (dark blue), D2, (light blue) and G2 (black), and pinewood sets E (dark green), F (light green) and G1 (gray), (B) after BT (green), CT (blue) or NT (gray) for oak sets B (fresh wood, - ) and D1 (waterlogged wood, dashed line - -).

In addition, ATR-FTIR ratios were calculated (Table 2). For fresh wood, we observed a general decrease of the ratios suggesting a degradation of holocellulose content after artificial degradation and contamination (i.e., sets A1, A2, B and E). In addition, pinewood samples from sets E and F showed higher ratios values.

Table 2. ATR-FTIR ratios $(\mathrm{R} 1=\mathrm{I}(1158) / \mathrm{I}(1506), \mathrm{R} 2=\mathrm{I}(1374) / \mathrm{I}(1506)$ and $\mathrm{R} 3=\mathrm{I}(1034) / \mathrm{I}(1506))$ calculated for all sets compared with fresh balsa, oak and pine wood ( \pm standard deviation).

\begin{tabular}{ccccc}
\hline Set Name & Extraction Method & $\mathbf{R 1}(\mathbf{H} / \mathbf{L})$ & $\mathbf{R} 2(\mathbf{C} / \mathbf{L})$ & $\mathbf{R 3}(\mathbf{H} / \mathbf{L})$ \\
\hline Fresh balsa & - & $1.16( \pm 0.05)$ & $1.07( \pm 0.03)$ & $1.65( \pm 0.24)$ \\
Fresh oak & - & $1.08( \pm 0.04)$ & $1.01( \pm 0.03)$ & $1.55( \pm 0.20)$ \\
Fresh pine & - & $1.05( \pm 0.01)$ & $1.00( \pm 0.00)$ & $1.21( \pm 0.04)$ \\
& BT & $0.91( \pm 0.03)$ & $0.94( \pm 0.01)$ & $1.05( \pm 0.07)$ \\
A1 & CT & $0.93( \pm 0.02)$ & $0.94( \pm 0.00)$ & $1.10( \pm 0.07)$ \\
& NT & $0.88( \pm 0.02)$ & $0.93( \pm 0.01)$ & $0.97( \pm 0.05)$ \\
A2 & BT & $0.93( \pm 0.02)$ & $0.94( \pm 0.01)$ & $1.07( \pm 0.07)$ \\
& CT & $0.92( \pm 0.03)$ & $0.95( \pm 0.01)$ & $1.07( \pm 0.07)$ \\
& NT & $0.89( \pm 0.02)$ & $0.94( \pm 0.01)$ & $0.99( \pm 0.05)$ \\
B & BT & $0.95( \pm 0.04)$ & $0.94( \pm 0.01)$ & $1.21( \pm 0.13)$ \\
& CT & $0.98( \pm 0.03)$ & $0.94( \pm 0.01)$ & $1.30( \pm 0.11)$ \\
C & NT & $0.92( \pm 0.04)$ & $0.98( \pm 0.03)$ & $1.17( \pm 0.11)$ \\
& BT & $0.87( \pm 0.01)$ & $0.91( \pm 0.01)$ & $0.95( \pm 0.03)$ \\
& CT & $0.85( \pm 0.01)$ & $0.91( \pm 0.01)$ & $0.90( \pm 0.03)$ \\
D1 & NT & $0.90( \pm 0.01)$ & $0.92( \pm 0.01)$ & $0.99( \pm 0.03)$ \\
& BT & $0.89( \pm 0.02)$ & $0.91( \pm 0.01)$ & $0.98( \pm 0.03)$ \\
& CT & $0.88( \pm 0.03)$ & $0.91( \pm 0.01)$ & $0.95( \pm 0.08)$ \\
D2 & NT & $0.90( \pm 0.01)$ & $0.92( \pm 0.01)$ & $1.01( \pm 0.03)$ \\
& BT & $0.86( \pm 0.01)$ & $0.91( \pm 0.01)$ & $0.94( \pm 0.03)$ \\
& CT & $0.87( \pm 0.06)$ & $0.92( \pm 0.03)$ & $0.96( \pm 0.12)$ \\
& NT & $0.85( \pm 0.02)$ & $0.92( \pm 0.00)$ & $0.91( \pm 0.04)$ \\
& BT & $1.01( \pm 0.06)$ & $0.97( \pm 0.02)$ & $1.47( \pm 0.20)$ \\
& CT & $1.00( \pm 0.05)$ & $0.96( \pm 0.02)$ & $1.42( \pm 0.18)$ \\
NT & $0.97( \pm 0.03)$ & $0.95( \pm 0.01)$ & $1.24( \pm 0.11)$ \\
\hline
\end{tabular}


Table 2. Cont.

\begin{tabular}{ccccc}
\hline Set Name & Extraction Method & R1 (H/L) & R2 (C/L) & R3 (H/L) \\
\hline \multirow{3}{*}{ F } & BT & $0.95( \pm 0.09)$ & $0.95( \pm 0.03)$ & $1.31( \pm 0.37)$ \\
& CT & $0.98( \pm 0.09)$ & $0.96( \pm 0.03)$ & $1.37( \pm 0.34)$ \\
& NT & $0.98( \pm 0.06)$ & $0.95( \pm 0.02)$ & $1.27( \pm 0.26)$ \\
G1 & BT & $0.85( \pm 0.02)$ & $0.92( \pm 0.01)$ & $0.93( \pm 0.07)$ \\
& CT & $0.87( \pm 0.04)$ & $0.93( \pm 0.02)$ & $0.98( \pm 0.10)$ \\
& NT & $0.84( \pm 0.01)$ & $0.92( \pm 0.01)$ & $0.90( \pm 0.06)$ \\
G2 & BT & $0.85( \pm 0.01)$ & $0.91( \pm 0.01)$ & $0.89( \pm 0.02)$ \\
& CT & $0.88( \pm 0.03)$ & $0.91( \pm 0.01)$ & $0.95( \pm 0.09)$ \\
\hline
\end{tabular}

We noticed that after extraction, whatever the treatment (i.e., BT or CT) applied, the ratios calculated were quite similar with the one before extraction (NT). This observation suggests that the extraction methods did not have any impact on the wood matrix. This is even more evident for not artificially contaminated sets (i.e., sets D1, D2, G1 and G2).

\subsection{Raman Spectroscopy}

First, the reference compounds were analyzed. Raman spectra obtained are displayed in Figure 3. Spectra obtained from goethite, hematite, sulfur and pyrite were similar to that described in the literature [10,36]. For the synthetized mackinawite, the bands obtained at 119(s), 235(w), 282(s), 320(w), $360(\mathrm{~s})$ and $452(\mathrm{~m}) \mathrm{cm}^{-1}$ suggest the formation of an intermediary phase, partially oxidized mackinawite $\mathrm{Fe}_{1-\mathrm{x}} \mathrm{S}[10]$.

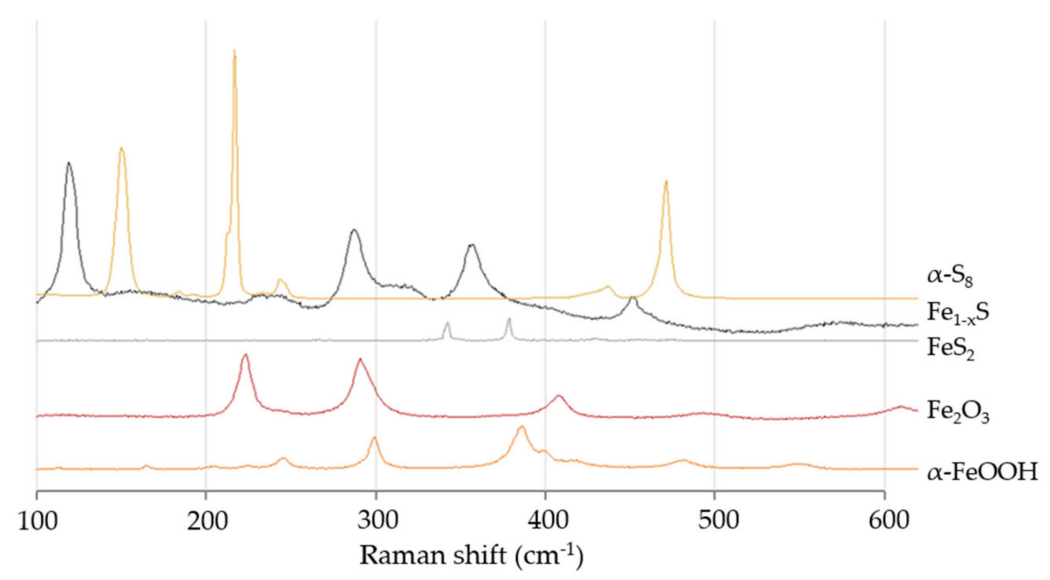

Figure 3. Raman spectra of reference compounds goethite $(\alpha-\mathrm{FeOOH})$, hematite $\left(\mathrm{Fe}_{2} \mathrm{O}_{3}\right)$, sulfur $\left(\alpha-\mathrm{S}_{8}\right)$ pyrite $\left(\mathrm{FeS}_{2}\right)$ and partially oxidized mackinawite $\left(\mathrm{Fe}_{1-\mathrm{x}} \mathrm{S}\right)$.

Analyses of the wood samples before extraction showed that reduced sulfur compounds were present on the artificially contaminated samples. A1, A2, C, E and F sets displayed the same spectrum as reference $\mathrm{Fe}_{1-\mathrm{x}} \mathrm{S}$ (Figure $4 \mathrm{~B}$ ). Elemental sulfur was identified only on set $\mathrm{B}$ samples (fresh oak) with characteristics bands at 152(m), 220(s) and $473(\mathrm{~m}) \mathrm{cm}^{-1}$ (Figure 4A). Finally, Raman spectra for sets D1, D2, G1 and G2 did not reveal the presence of any inorganic compounds. This observation is in contradiction with the previous spot tests performed on wood samples from sets D1, D2, G1 and G2. 
A.

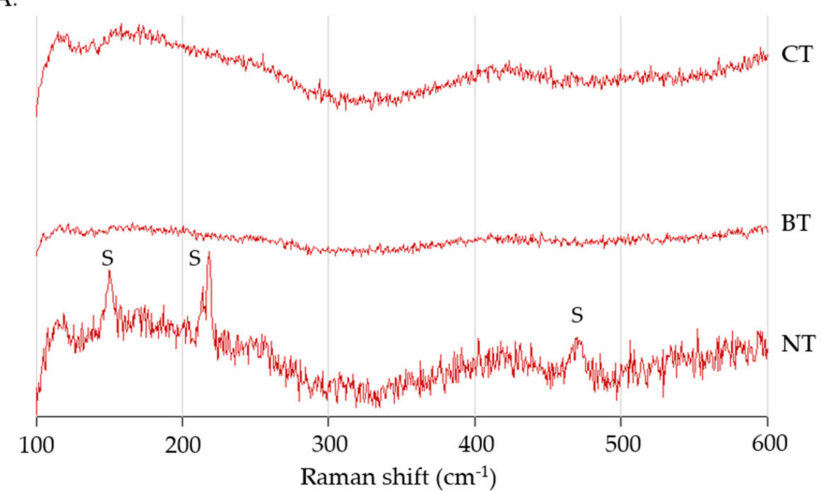

B.

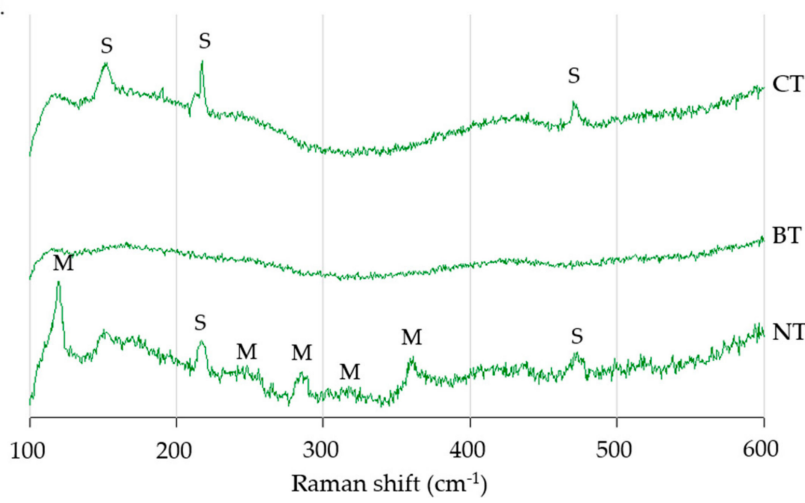

Figure 4. Raman spectra obtained on A. set B (fresh oak) and B. set E (fresh pine) untreated (NT), biologically treated (BT) and chemically treated (CT); with sulfur (S) and partially oxidized mackinawite (M) characteristics shifts indicated.

After extraction, no reduced sulfur compounds were detected on BT samples suggesting that the extraction seemed successfully achieved (Figure 4). While elemental sulfur was still identified on some CT samples.

For all sets, some bands at 400,580, 650, 930, 1270, 1330 and $1480 \mathrm{~cm}^{-1}$ (Figure 5) were observed and were attributed to wood substrate [37]. All the identified compounds are summarized in Table 3.

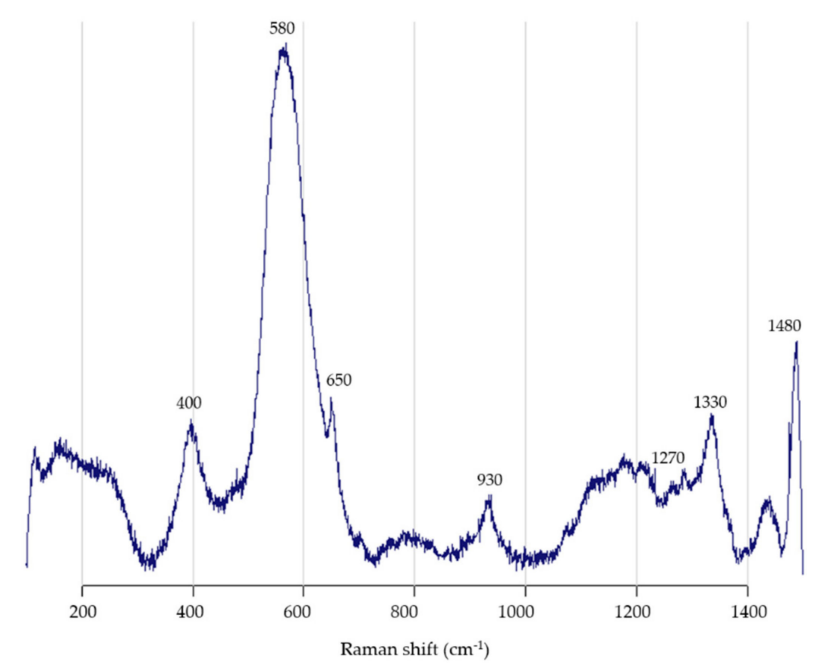

Figure 5. Representative Raman spectrum obtained on wood substrate. 
Table 3. Compounds identified by Raman spectroscopy based on the extraction methods.

\begin{tabular}{cccc}
\hline Set Name & Sulfur & Partially Oxidized Mackinawite & Wood Substrate \\
\hline A1 & NT & NT & NT, BT, CT \\
A2 & CT & NT & NT, BT, CT \\
B & NT & & NT, BT, CT \\
C & CT & NT & NT, BT, CT \\
D1 & & & NT, BT, CT \\
D2 & & NT & NT, BT, CT \\
E & NT, CT & NT & NT, BT, CT \\
F & CT & & NT, BT, CT \\
G1 & & & NT, BT, CT \\
G2 & & & NT, BT, CT \\
\hline
\end{tabular}

\subsection{Chemometrics}

PCA analyses were carried out on the ATR-FTIR dataset before and after extraction. Before extraction, different clusters can be observed (Figure 6A). All three species of fresh wood gathered with an overlapping of fresh balsa and oak samples. On the other side, all the archaeological samples clustered and overlapped. Only samples from set F (lake pine) differed slightly from the other sets, suggesting that this set is less degraded.

After extraction, all sets gathered, independently of the extraction method applied (Figure 6B). Some clusters can be observed. Sets E and F (artificially contaminated pinewood) overlapped, A1 and A2 sets (balsa) also overlapped as for sets C, D1, D2 and G2 (archaeological oak wood). Only exception is set G1, overlapping with archaeological oak sets though G1 is archaeologic pinewood. It seemed that when a certain state of degradation is reached, the wood species does not influence the classification. These clusters are related to wood composition, which is identical within each cluster.

A.

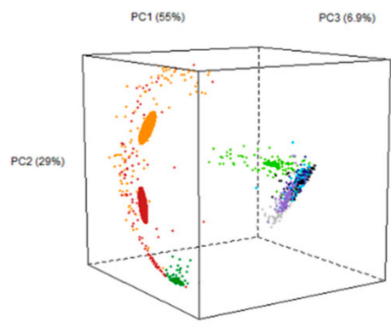

SelA SetB SelC SetD1 SetD2 SetE set

C.

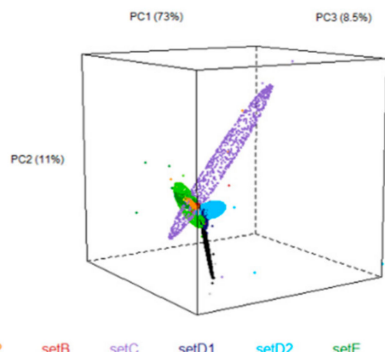

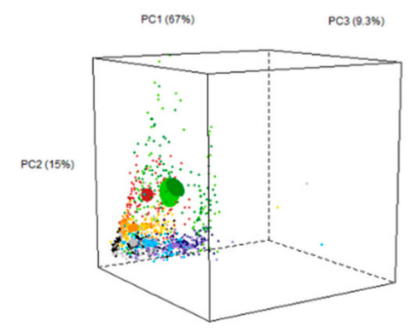

D.

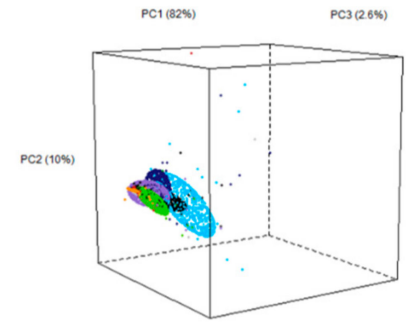

Figure 6. PCA score plots for ATR-FTIR (A). before and (B). after extraction and for Raman (C). before and (D). after extraction.

LASSO regression was carried out on the ATR-FTIR dataset. All the analyses showed that the vibrational band at $1158 \mathrm{~cm}^{-1}$, assigned to $\mathrm{C}-\mathrm{O}-\mathrm{C}$ vibration in holocellulose, is the main important variable regarding the classification of our data.

PCA was also performed for the Raman dataset. No distinction could be made between artificially contaminated and waterlogged wood (Figure 6C) or among the extraction methods (Figure 6D). Deeper analyses were performed on the entire dataset through LASSO regression. 
At first, spectra of the reference compounds were used as model. Then, the model was applied on the Raman spectra dataset to predict its classification. However, the results obtained showed that our model was not optimal as hematite bands were the main variables employed for the classification. The interpretation of the experimental data needs further investigation.

\section{Discussion}

\subsection{ATR-FTIR Spectroscopy}

Vibrational bands assigned to carbohydrates at 1034 and $1059 \mathrm{~cm}^{-1}$ were observed for fresh samples but their intensities were lower for archaeological samples (except set $\mathrm{F}$ ). This is in correlation with the R1 (H/L) and R2 (C/L) ratios calculated. Indeed, the fresh wood samples showed ratios in the range 1.00-1.50 while ratios of archaeological wood (oak and pine) displayed lower ratio values (0.80-1.00). Previous studies of modelling waterlogged wood have demonstrated that these ratios decreased after artificial contamination of the fresh samples [14]. This is also observed here, with ratios of NT samples being lower than the ratios of fresh balsa, oak and pine wood species. Moreover, the ratios after extraction remained in the same range. It can then be ascertained that the decrease of the ratios was not due to the extraction but to the artificial contamination protocol applied on some wood mock-ups.

Comparing the treatments (BT, CT) with NT samples, we can observe that the ratios were in the same range for each set. The treatment applied on the samples did not affect the carbohydrates content, whether it was a chemical or a biological treatment. Regarding the degradation criterion, none of the extraction methods enhanced wood degradation suggesting that they all guarantee the preservation of waterlogged wood objects. Previous study has already demonstrated that $T$. denitrificans was harmless for wood substrate [14]. Iron extraction with siderophores as first extraction step did not interfere with the substrate neither.

However, R3 ratio displayed higher values for sets $\mathrm{E}$ (fresh pine) and F (lake pine). Both these sets are pinewood artificially contaminated. $\mathrm{R} 3$ ratio is based on the height of the vibrational band at $1034 \mathrm{~cm}^{-1}$ attributed to $\mathrm{C}-\mathrm{O}$ stretching of holocellulose and lignin [34]. The artificial contamination did not degrade wood content as the values for NT samples in sets E and F are in the same range as fresh pine. The ratios increased after extraction treatment suggesting that lignin content was degraded. This is an extra correlation for these sets. Indeed, all mock-ups in set $\mathrm{F}$ showed very intense vibrational bands at 1304 and $1059 \mathrm{~cm}^{-1}$ even though this pinewood was dated from the nineteenth century. Comparing with literature, waterlogged pine wood generally present higher ratio values than oak species [38]. It seems that the impregnation protocol has a different effect depending on wood specie leading to different states of carbohydrates degradation. Intern structure of these pinewood species (porosity, presence of resin canals) may lead to different degradation processes. For example, Neolithic pine was reported to be a yellow and hard wood while Neolithic oak was described as yellow-red wood with the heartwood well preserved but the sapwood often destroyed [39]. To reach similar state of degradation, a longer water pre-immersion time or increase of vacuum, forcing the structure to collapse should be applied on fresh wood samples in further experiments.

Results obtained from the ratios imply that no cellulosic degradation occurred during extraction. However, visual observation showed an important aesthetic change, especially regarding chemically treated samples (Figure 1). If the ratios are not impacted, minor wood components such as extractives may react during extraction. Another reason could be that inorganic salts react with the persulfate, leading to their dissolution and then discoloration of the wood surface.

PCA analysis was carried out on the same dataset. The results showed that before artificial contamination fresh and archaeological wood samples can be differentiated. The clustering is based on the frequencies in the range $1010-1060 \mathrm{~cm}^{-1}$ and $3250-3270 \mathrm{~cm}^{-1}$. These ranges affected the first loadings for the PCA analysis. The range $3250-3270 \mathrm{~cm}^{-1}$ is assigned to $\mathrm{O}-\mathrm{H}$ stretching vibrations [34]. This proves that the lignin parts were not the main factor to cluster this dataset. PCA analysis is then 
based on the carbohydrates content and allows differentiating the sets. However, after extraction, as observed before for spectra and ratios, it was more complicated to cluster data. PCA score plots obtained showed that all the samples gathered. Sets E and F clustered, validating the observations above. This cluster proved that pine, whether fresh or slightly decayed, presents similar behavior. Oak samples (sets C, D1, D2 and G2) also cluster together. All these sets are from archaeological wood. Their confident ellipses overlapped the one of set G1 (archaeological pine) meaning that spectra obtained for all the sets present similarities. All archaeological oak wood sets present similar state of degradation as well as set G1. However, set B (fresh oak) did not cluster with the other oak groups but was closer to sets $\mathrm{E}$ and $\mathrm{F}$ (fresh and lake pine, respectively) meaning that the fresh oak degradation was not as efficient as expected. Both fresh oak and pine wood species were not as degraded as expected during the artificial contamination protocol. In addition, their spectra were similar to the one of set $\mathrm{F}$ samples. Application of artificial contamination of fresh oak and pine led to a degradation state similar to lake pine. The ranges from $810-850 \mathrm{~cm}^{-1}, 1020-1065 \mathrm{~cm}^{-1}$ and $1508-1558 \mathrm{~cm}^{-1}$ were the main frequencies to cluster the samples. After extraction, we noticed that the lignin range is as important as carbohydrates range meaning that this wood component interfered in the clustering. Lignin vibrational bands are more intense compare to before extraction. This could suggest that the carbohydrates vibrational bands are as intense as the lignin ones.

LASSO analysis validated these observations. All three factors Wood Species, Wood Type and Artificially Contamination mainly depended of the variable $1158 \mathrm{~cm}^{-1}$, which is the vibrational band attributed to $\mathrm{C}-\mathrm{O}-\mathrm{C}$ vibration within holocellulose. The statistical approach performed showed that carbohydrates content was the main variable to differentiate, classify and interpret the dataset.

\subsection{Raman Spectroscopy}

In parallel, Raman spectroscopy was performed on the samples to identify the compounds present. Based on a comparison with the reference compounds (Figure 3), it can be proven that the impregnation protocol applied on some sets to perform an artificial contamination led to the formation of partially oxidized mackinawite $\mathrm{Fe}_{1-x} \mathrm{~S}$. Only set $\mathrm{B}$ samples displayed different spectra with elemental sulfur $\mathrm{S}_{8}$ detected. The precipitation of sulfur may be due to the wood matrix. Indeed, fresh oak wood presents a high content of tannin [40]. This was confirmed by analyzing the precipitates obtained from the water pre-immersion solution (data not showed). If tannins were released during the water pre-immersion phase, it is likely that they were also released in the impregnation solution. As the first step of the impregnation with ferrous chlorine solution lasted $4 \mathrm{~h}$, it is possible that the tannins released reacted with iron ions present in solution to form iron-tannin complexes. Iron will then not be available to react with the sulfide ions during the second step of the impregnation protocol. On the contrary, elemental sulfur was not formed on archaeological oak sets since the tannins were absent as previously degraded during burial time. Moreover, the water solution where oak samples were pre-immersed turned orange while this was not the case for sets A1 and A2 (fresh balsa) and set E (fresh pine) whose pre-immersion water solutions remained colorless. The color of the solution for fresh balsa and fresh pine suggested that no release of tannins occurred during the water pre-immersion step and explain why iron sulfides were formed afterwards during the impregnation step. In literature, it was demonstrated that iron sulfides can be oxidized by microorganisms through two different mechanisms: thiosulfate and polysulfide pathways. These mechanisms depend of the acid solubility of the iron sulfide species [41]. Indeed, pyrite is an acid-insoluble sulfide while mackinawite or partially oxidized mackinawite are acid-soluble compounds [42]. Only acid-soluble iron sulfides species were here investigated, and the efficiency of BT assessed only for this family of compounds.

However, no iron sulfide compounds were identified on sets D1, D2, G1 and G2. The spot tests previously performed validated the presence of iron and sulfate species. Their concentration within archaeological wood may be low or the contamination heterogeneous, explaining why nothing was detected by Raman. 
After extraction, iron sulfides compounds were absent from all BT samples. It seemed then that at least on surface, the extraction of $\mathrm{Fe} / \mathrm{S}$ species with the proposed microbial treatment was efficient. On the contrary, CT samples still presented some reduced sulfur compounds, mainly elemental sulfur. Especially, as can be seen on Table 2, sulfur was identified on sets A2, E and F. As observed with previous ATR-FTIR results, different chemical extraction rates may be observed for pinewood. In fact, both sets of fresh and lake pine presented sulfur, but all iron seemed extracted. The chemical treatment allowed uptaking the iron, at least on surface, but the sulfur was not complexed and solubilized.

These first results showed that BT, even though it lasted 30 days against 8 days for $\mathrm{CT}$, was more efficient regarding both iron and sulfur extraction. However, the analyses were only performed on surface of the samples and did not allow evaluating the complete extraction of $\mathrm{Fe} / \mathrm{S}$ species within the wood structure. Further analyses should be performed in the samples core, before and after extraction, to evaluate how deep extraction of $\mathrm{Fe} / \mathrm{S}$ species occurred. Moreover, contamination with iron disulfides species should be performed to evaluate if BT can be applied for any sulfide-metal extraction.

Furthermore, Raman analyses displayed bands not attributed to reduced sulfur compounds or iron oxides. The strongest bands were in the range $1200-1500 \mathrm{~cm}^{-1}$. Investigation of these bands showed that they may be due to the wood substrate. If Raman was not considered to evaluate wood degradation, these results demonstrated that it could be employed as complementary method with ATR-FTIR spectroscopy to determine the state of degradation of wood.

PCA analyses carried out on the dataset before and after extraction did not show clusters suggesting a poor distinction among the sets. However, previous observations showed that no reduced sulfur species were identified for sets D1, D2, G1 and G2 before extraction. A plausible explanation for the clustering of all sets together may be due to the presence of the vibrational bands attributed to the wood substrate. Indeed, for all, a similar pattern was observed and assigned to the wood based on previous studies [37]. This pattern may interfere and be the main variable for the PCA analyses. However, similar analyses performed only in the range $100-600 \mathrm{~cm}^{-1}$ displayed same results with all samples clustering. It seemed that PCA was not the most convenient method to interpret this dataset. Additional analyses through Hierarchical Clustering Analysis (HCA) and spectra distance (data not shown) did not provide further information.

Deeper investigation was then performed, similar to the one applied for the ATR-FTIR dataset. The regression performed depending of the five reference compounds (i.e., partially oxidized mackinawite, sulfur, pyrite, goethite and hematite) showed that the main variable were hematite bands for Raman spectra. This result already showed that the prediction model was not well adapted for the dataset. Moreover, the application of the model to the dataset resulted in false error regarding reduced sulfur compounds. The prediction model should be optimized. As described in Section 3.2., no iron oxide compounds were observed on the surface of the samples. Their characteristic bands should not be the main variable to understand and classify the Raman dataset.

This study demonstrated that PCA-LASSO analyses allow validating our ATR-FTIR dataset. However, concerning Raman spectroscopy, these two methods did not validate the observations. Further statistical analyses such as one-way ANOVA or K nearest neighbor (KNN) analyses could be applied on the Raman dataset. Results then obtained could help to understand the ones observed so far and to provide a prediction model for further analyses.

\subsection{Application to Real Artefacts}

This study proves the feasibility of a biological extraction method for Fe and S species. However, as discussed in Section 4.2., the analyses were performed only on the surface of the samples and not in the core. Further investigations should be carried out to validate the efficiency of the microorganisms to extract the species within the objects. In addition, it has been reported that for the larger objects, such as the Vasa warship, iron and sulfur species were detected in the two first centimeters [43]. The proposed biological treatment would be able to reach such depth for large objects to have an optimal extraction rate if small-shaped bacteria are employed. T. denitrificans are a short rod-shaped bacteria of dimensions 
$0.5 \times 1-3 \mu \mathrm{m}$ [44] and the typical range of wood pores is $150-200 \mu \mathrm{m}$ for hardwood, such as oak, [45] and $30-40 \mu \mathrm{m}$ for softwood, such as pine [46]. They can penetrate within the wood pores and then have the capacity to oxidize iron sulfides compounds in situ.

An application on such larger objects should also be considered. In this study, the samples were cubes of $2 \times 2 \times 2 \mathrm{~cm}^{3}$. If some waterlogged archaeological wooden objects may be of similar shape and/or volume, most of them are more massive. Indeed, the main waterlogged artefacts are everyday life objects, from different periods and civilizations [47-49]. They range from buckets, tools to boats. For instance, over 500 boats have been excavated from Swiss lakes since 1850 [49]. In this case, a treatment per immersion requires an infrastructure adapted to such artefacts, with large immersion installation baths, as it is the case in ARC-Nucleart, Grenoble (FR) [50]. Another solution would be application by spray, as developed for the consolidation of the Vasa warship at the Mary Rose Trust, Portsmouth (UK). Another point should be the duration of the treatment. An adaptation of the time of the treatment should be considered to ascertain that the extraction of harmful species was efficient till the core of the objects.

\section{Conclusions}

With the perspective of developing an innovative green biological extraction method, ATR-FTIR and Raman spectroscopies methods were used to compare the efficiency of biological treatment over commonly used chemical extraction method. First results were promising. After extraction, reduced sulfur compounds identified by Raman spectroscopy were not identified anymore after biological treatment (BT) while sulfur was still present for fresh and lake pine after chemical treatment (CT). The wood species may have more impact on the efficiency of CT but not BT as extraction on surface seemed efficient of all BT mock-ups. However, it is worth mentioning that both treatments seemed to be quite smooth methods as no further wood degradation was observed with ATR-FTIR measurements.

The statistical approach performed on the spectroscopic dataset validated our observations regarding ATR-FTIR measurements. Different regression and prediction models should be investigated for Raman spectra, to have a better understanding from the data available. In the following months, the consolidation phase in PEG baths foreseen within the MICMAC project will be applied to assess the long-term behavior of the samples after different extraction methods. Prediction models will be then optimized to classify spectroscopic data before and after extraction, as well as after consolidation. As well, Inductively Coupled Plasma Optical Emission Spectrometry (ICP-OES) is foreseen to evaluate the extraction rate of Fe and S species for each extraction method studied. Raman analyses of the samples core will also be performed to evaluate how deep samples are previously impregnated with iron and sulfur species as well as how deep the extraction is effective. Furthermore, imaging analyses (i.e., Raman and Scanning Electron Microscope imaging) of woods samples are planned before and after treatment to evaluate possible changes in the wood structure (cell collapse or swelling for example).

Author Contributions: Conceptualization, E.J.; methodology, M.M., M.A.-B., T.L., E.C., F.M.-D., J.S., K.S.-O. and E.J.; software, M.M.; validation, M.M., M.A.-B. and E.J.; formal analysis, M.M.; investigation, M.M., M.A.-B., T.L and E.C.; data curation, M.M.; writing—original draft preparation, M.M., E.J.; visualization, M.M.; supervision, E.J.; project administration, E.J.; funding acquisition, E.J. All authors have read and agreed to the published version of the manuscript.

Funding: This research was funded by the Swiss National Science Foundation (SNSF); grant number PP00P2_163653/1, MICMAC (MICrobes for Archaeological wood Conservation) project 2016-2020.

Acknowledgments: The authors acknowledge the Swiss National Museum and the Archeological Service of Bern canton for their contribution to the project and Bryan Hanson from DePauw University, United States of America, for his help regarding the ChemoSpec package.

Conflicts of Interest: The authors declare no conflict of interest. 


\section{References}

1. Björdal, C.G.; Daniel, G.; Nilsson, T. Depth of burial, an important factor in controlling bacterial decay of waterlogged archaeological poles. Int. Biodeterior. Biodegrad. 2000, 45, 15-26. [CrossRef]

2. Björdal, C.G.; Nilsson, T. Reburial of shipwrecks in marine sediments: a long-term study on wood degradation. J. Archaeol. Sci. 2008, 35, 862-872. [CrossRef]

3. Björdal, C.G.; Nilsson, T.; Daniel, G. Microbial decay of waterlogged archaeological wood found in Sweden. Applicable to archaeology and conservation. Int. Biodeterior. Biodegrad. 1999, 43, 63-73. [CrossRef]

4. Fors, Y.; Richards, V. The effects of the ammonia neutralizing treatment on marine archaeological Vasa wood. Stud. Conserv. 2010, 55, 41-54. [CrossRef]

5. Fors, Y.; Sandström, M. Sulfur and iron in shipwrecks cause conservation concerns. Chem. Soc. Rev. 2006, 35, 399-415. [CrossRef]

6. Fors, Y.; Nilsson, T.; Risberg, E.D.; Sandström, M.; Torssander, P. Sulfur accumulation in pinewood (Pinus sylvestris) induced by bacteria in a simulated seabed environment: Implications for marine archaeological wood and fossil fuels. Int. Biodeterior. Biodegrad. 2008, 62, 336-347. [CrossRef]

7. Singh, A.P.; Butcher, J.A. Bacterial degradation of wood cell walls: A review of degradation patterns. J. Inst. Wood Sci. 1991, 12, 143-157.

8. Sørensen, J.; Christensen, D.; Jørgensen, B.B. Volatile Fatty acids and hydrogen as substrates for sulfate-reducing bacteria in anaerobic marine sediment. Appl. Environ. Microbiol. 1981, 42, 5-11. [CrossRef]

9. Rémazeilles, C.; Saheb, M.; Neff, D.; Guilminot, E.; Tran, K.; Bourdoiseau, J.A.; Sabot, R.; Jeannin, M.; Matthiesen, H.; Dillmann, P.; et al. Microbiologically influenced corrosion of archaeological artefacts: Characterisation of iron (II) sulfides by Raman spectroscopy. J. Raman Spectrosc. 2010, 41, 1425-1433. [CrossRef]

10. Rémazeilles, C.; Tran, K.; Guilminot, E.; Conforto, E.; Refait, P. Study of Fe (II) sulphides in waterlogged archaeological wood. Stud. Conserv. 2013, 58, 297-307. [CrossRef]

11. Wetherall, K.M.; Moss, R.M.; Jones, A.M.; Smith, A.D.; Skinner, T.; Pickup, D.M.; Goatham, S.W.; Chadwick, A.V.; Newport, R.J. Sulfur and iron speciation in recently recovered timbers of the Mary Rose revealed via X-ray absorption spectroscopy. J. Archaeol. Sci. 2008, 35, 1317-1328. [CrossRef]

12. Preston, J.; Smith, A.D.; Schofield, E.J.; Chadwick, A.V.; Jones, M.A.; Watts, J.E.M. The effects of Mary Rose conservation treatment on iron oxidation processes and microbial communities contributing to acid production in marine archaeological timbers. PLoS One 2014, 9. [CrossRef] [PubMed]

13. Almkvist, G.; Norbakhsh, S.; Bjurhager, I.; Varmuza, K. Prediction of tensile strength in iron-contaminated archaeological wood by FT-IR spectroscopy-a study of degradation in recent oak and Vasa oak. Holzforschung 2016, 70, 855-865. [CrossRef]

14. Berenguer, M.A.; Monachon, M.; Jacquet, C.; Junier, P.; Rémazeilles, C.; Schofield, E.J.; Joseph, E. Biological oxidation of sulfur compounds in artificially degraded wood. Int. Biodeterior. Biodegradation 2019, 141, 62-70. [CrossRef]

15. Sandström, M.; Jalilehvand, F.; Damian, E.; Fors, Y.; Gelius, U.; Jones, M.; Salomé, M. Sulfur accumulation in the timbers of King Henry VIII's warship Mary Rose: A pathway in the sulfur cycle of conservation concern. Proc. Natl. Acad. Sci. USA 2005, 102, 14165-14170. [CrossRef]

16. Almkvist, G.; Persson, I. Extraction of iron compounds from wood from the Vasa. Holzforschung 2006, 60, 678-684. [CrossRef]

17. Junier, P.; Joseph, E. Microbial biotechnology approaches to mitigating the deterioration of construction and heritage materials. Microb. Biotechnol. 2017, 10, 1145-1148. [CrossRef]

18. Joseph, E.; Junier, P. Metabolic processes applied to endangered metal and wood heritage objects: Call a microbial plumber! N. Biotechnol. 2019. [CrossRef]

19. Albini, M.; Letardi, P.; Mathys, L.; Brambilla, L.; Schröter, J.; Junier, P.; Joseph, E. Comparison of a bio-based corrosion inhibitor versus benzotriazole on corroded copper surfaces. Corros. Sci. 2018, 143, 84-92. [CrossRef]

20. Tran, K.; Bertout, N.; Dalard, F.; Magnin, J.P. Trials on chemical and microbiological processes for the oxidation of sulphur compounds in archaeological wood. In Proceedings of the 9th ICOM Group on Wet Organic Archaeological Materials Conference, Copenhagen, Denmark, 7-11 June 2004; pp. 227-241.

21. Bosch, J.; Lee, K.Y.; Jordan, G.; Kim, K.W.; Meckenstock, R.U. Anaerobic, nitrate-dependent oxidation of pyrite nanoparticles by thiobacillus denitrificans. Environ. Sci. Technol. 2012, 46, 2095-2101. [CrossRef] 
22. Albelda-Berenguer, M.; Monachon, M.; Joseph, E. Siderophores: From natural roles to potential applications. Adv. Appl. Microbiol. 2019, 106, 193. [PubMed]

23. Neilands, J.B. Siderophores: structure and function of microbial iron transport compounds. J. Biol. Chem. 1995, 270, 26723-26726. [CrossRef]

24. Rapti, S.; Rivers, S.; Pournou, A. Removing iron corrosion products from museum artefacts: Investigating the effectiveness of innovative green chelators. In Proceedings of the International Conference "Science in Technology", SCinTE, Athens, Greece, 5-7 November 2015.

25. Homann, V.V.; Edwards, K.J.; Webb, E.A.; Butler, A. Siderophores of Marinobacter aquaeolei: Petrobactin and its sulfonated derivatives. BioMetals 2009, 22, 565-571. [CrossRef] [PubMed]

26. Pelé, C.; Guilminot, E.; Labroche, S.; Lemoine, G.; Baron, G. Iron removal from waterlogged wood: Extraction by electrophoresis and chemical treatments. Stud. Conserv. 2013, 0,1-17. [CrossRef]

27. Sandak, A.; Sandak, J.; Babiński, L.; Pauliny, D.; Riggio, M. Spectral analysis of changes to pine and oak wood natural polymers after short-term waterlogging. Polym. Degrad. Stab. 2014, 99, 68-79. [CrossRef]

28. Norbakhsh, S.; Bjurhager, I.; Almkvist, G. Impact of iron (II) and oxygen on degradation of oak-Modeling of the Vasa wood. Holzforschung 2014, 68, 649-655. [CrossRef]

29. Odegaard, N.; Carroll, S.; Zimmt, W.S. Material Characterization Tests for Objects of Art and Archaeology, 2nd ed.; Archetype Publications Ltd.: London, UK, 2000.

30. Giachi, G.; Guidotti, M.C.; Lazzeri, S.; Sozzi, L.; Macchioni, N. Wood identification of the headrests from the collection of the Egyptian Museum in Florence. J. Archaeol. Sci. Rep. 2016, 9, 340-346. [CrossRef]

31. Dobrică, I.; Bugheanu, P.; Stănculescu, I.; Ponta, C. FT-IR spectral data of wood used in Romanian. Analele Univ. din Bucuresti 2008, I, 33-37.

32. Bourdoiseau, J.A.; Jeannin, M.; Sabot, R.; Rémazeilles, C.; Refait, P. Characterisation of mackinawite by Raman spectroscopy: Effects of crystallisation, drying and oxidation. Corros. Sci. 2008, 50, 3247-3255. [CrossRef]

33. Schwertmann, U. Solubility and dissolution of iron oxides. Iron Nutr. Interact. Plants 1991, 130, 1-25.

34. Pandey, K.K.; Theagar, K.S. Analysis of wood surfaces and ground wood by diffuse reflectance (DRIFT) and photoacoustic (PAS) Fourier transform infrared spectroscopic techniques. Holz als Roh-und Werkst 1997, 55, 383-390. [CrossRef]

35. Pandey, K.K.; Nagveni, H.C. Rapid characterisation of brown and white rot degraded chir pine and rubberwood by FTIR spectroscopy. Holz als Roh-und Werkst. 2007, 65, 477-481. [CrossRef]

36. Bouchard, M.; Smith, D.C. Catalogue of 45 reference Raman spectra of minerals concerning research in art history or archaeology, especially on corroded metals and coloured glass. Spectrochim. Acta-Part A Mol. Biomol. Spectrosc. 2003, 59, 2247-2266. [CrossRef]

37. Agarwal, U.P.; Ralph, S.A. FT-Raman spectroscopy of wood: Identifying contributions of lignin and carbohydrate polymers in the spectrum of black spruce (Picea mariana). Appl. Spectrosc. 1997, 51, 1648-1655. [CrossRef]

38. Giachi, G.; Capretti, C.; Macchioni, N.; Pizzo, B.; Donato, I.D. A methodological approach in the evaluation of the efficacy of treatments for the dimensional stabilisation of waterlogged archaeological wood. J. Cult. Herit. 2010, 11, 91-101. [CrossRef]

39. Schweingruber, F.H. Microscopic Wood Anatomy; Swiss Federal Institute of Forestry Research: Birmensdorf, Switzerland, 1978.

40. Paaver, U.; Matto, V.; Raal, A. Total tannin content in distinct Quercus robur L. galls. J. Med Plants Res. 2010, 4, 702-705.

41. Sand, W.; Gehrke, T.; Jozsa, P.-G.; Schippers, A. (Bio)chemistry of bacterial leaching-Direct vs. indirect bioleaching. Hydrometallurgy 2001, 59, 159-175. [CrossRef]

42. Brandl, H. Microbial leaching of metals. In Proceeding of the Biotechnology Set; Wiley-VCH Verlag GmbH: Weinheim, Germany, 2001; pp. 191-224.

43. Sandström, M.; Jalilehvand, F.; Persson, I.; Gelius, U.; Frank, P.; Hall-Roth, I. Deterioration of the seventeenth-century warship Vasa by internal formation of sulphuric acid. Nature 2002, 415, 893-897. [CrossRef]

44. Kelly, D.P.; Wood, A.P. Confirmation of $\backslash$ emph $\{\{T\}$ hiobacillus denitrificans $\}$ as a species of the genus lemph $\{\{$ T\}hiobacillus $\}$, in the $\beta$-subclass of the $\backslash$ emph $\{\{P\}$ roteobacteria $\}$, with strain $\{\mathrm{NCIMB}\} 9548$ as the type strain. Int. J. Syst. Evol. Microbiol. 2000, 50, 547-550. [CrossRef] 
45. Wiedenhoeft, A.C.; Miller, R.B. 2. Structure and Function of Wood. Handb. Wood Chem. Wood Compos. 2005, 2, 9-33.

46. Gardner, D.J. Wood surface properties. Wood Struct. Prop. 2002, 2, 87-89.

47. McQueen, C.M.; Tamburini, D.; Łucejko, J.J.; Braovac, S.; Gambineri, F.; Modugno, F.; Colombini, M.P.; Kutzke, H. New insights into the degradation processes and influence of the conservation treatment in alum-treated wood from the Oseberg collection. Microchem. J. 2017, 132, 119-129. [CrossRef]

48. Tamburini, D.; Łucejko, J.J.; Modugno, F.; Colombini, M.P. Characterisation of archaeological waterlogged wood from Herculaneum by pyrolysis and mass spectrometry. Int. Biodeterior. Biodegradation 2014, 86, 142-149. [CrossRef]

49. Ramseyer, D. Archaeology and waterlogged wood. Museum Int. 1983, 39, 18-25. [CrossRef]

50. Caillat, L.; Meunier, L. Regeneration of PEG solutions used for waterlogged wood consolidation. In Proceedings of the 13th ICOM-CC Group on Wet Organic Archaeological Materials Conference, Florence, Italy, 16-21 May 2016; pp. 305-320.

(C) 2020 by the authors. Licensee MDPI, Basel, Switzerland. This article is an open access article distributed under the terms and conditions of the Creative Commons Attribution (CC BY) license (http://creativecommons.org/licenses/by/4.0/). 